\title{
Patient self-sampling: a cornerstone of future rheumatology care?
}

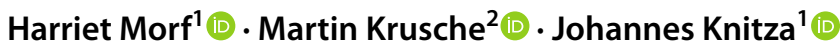

Received: 24 February 2021 / Accepted: 30 March 2021 / Published online: 10 April 2021

(c) The Author(s) 2021

Keywords Self-sampling $\cdot$ Rheumatology $\cdot$ Remote care $\cdot$ Personalised medicine $\cdot$ Web survey

\section{Dear Editor,}

With great interest, we read the letter by Cleaton et al. [1] regarding the impact of social distancing on a large cohort of rheumatology patients in the UK. The authors performed a large-scale evaluation to study the impact of COVID-19 on mortality, infection rate, shielding rates and compliance. Most patients followed specialists' advice on shielding, and the mortality rate for rheumatology patients was similar to regional reports. In another publication, the authors presented an innovative technique helping patients to self-score to stratify their own COVID-19 infection risk [2].

Confinement strategies and travel restrictions catalysed a rapid switch to remote rheumatologic consultations in many countries. Remote care in rheumatic and muscular diseases (RMDs) is a dynamic field [3], which will likely maintain importance even after the COVID-19 pandemic. Video consultations and electronic patient-reported outcomes (ePROs) have already been used in remote digital care [3]. Nevertheless, a cornerstone in diagnosis and management in routine rheumatology care is still missing.

In our opinion, self-sampling is indispensable when aiming to significantly improve patient-centred remote care in rheumatology. In rheumatology care, blood tests are crucial in establishing the correct diagnosis, and evaluating treatment safety and efficacy, and yet they represent a major reason for "non-shielding" physician visits. Self-sampling has successfully been introduced in other fields of medicine, such as diabetology [4] or anticoagulation management [5].

Johannes Knitza

johannes.knitza@uk-erlangen.de

1 Department of Internal Medicine 3-Rheumatology and Immunology, Friedrich-Alexander University ErlangenNürnberg, Erlangen, Germany

2 Department of Rheumatology and Clinical Immunology, Charité - Universitätsmedizin, Berlin, Germany
A pilot study showed that blood microsampling is a feasible and accurate method for monitoring hydroxychloroquine levels in rheumatoid arthritis patients [6]. Inflammatory markers, such as C-reactive protein (CRP), are especially crucial in the evaluation of inflammatory disease activity (i.e. DAS-28 or ASDAS), however, to our knowledge, only point-of-care tests [7] have yet been used.

We believe that COVID-19 will not only accelerate digitalisation in rheumatology care [3], but also in patient selfsampling. We recently reported that COVID-19 increased the acceptance of digital health applications among rheumatologists $(n=129)$ and patients $(n=299)$ in Germany [8]. Despite the current experimental status of self-sampling, we observed high acceptance rates among patients and rheumatologists. To our knowledge, this is the first published work to explore the acceptance of self-sampling in rheumatology. 128 (44\%) of patients and 50 (39\%) of rheumatologists were interested in using self-sampling in the future. Interestingly, male patients tended to be more in favour of self-sampling than female patients (67\% compared to $43 \%)(r=0.001$, $p=0.001)$. Furthermore, patients under the age of 60 years stated that they were more likely to use self-sampling in the future ( $p=0.05 ; r=0.137)$. Especially patients with spondyloarthritis (generally younger patients) expressed a positive opinion (53.7\%) concerning self-sampling. Additionally, we observed a positive correlation between the travel time to the rheumatologist and interest in self-sampling in male patients. In the case of more than $30 \mathrm{~min}$ travel time, we observed a significant correlation with interest in selfsampling $(p=0.027 ; r=0.418)$.

The advancement of self-sampling in rheumatology enables need adapted, low burden, patient-centered, flexible blood collection, ultimately empowering patients, rheumatologists and researchers alike.

Acknowledgements The authors declare that the article has not been published and is not under consideration for publication elsewhere. 
The manuscript has been read and approved by all authors. JK and HM drafted the manuscript. HM made the statistical analysis. MK revised the manuscript. The authors thank the following persons and communities for their great effort collecting data: Anna Kernder, Philipp Klemm, Diana Vossen, Isabell Haase, Johanna Mucke, Marco Meyer, Arnd Kleyer, Philipp Sewerin, Gerlinde Bendczuk, Sabine Eis, Peer Aries, Axel Hueber, Martin Welcker, Christopher Fiehn, Alexander Pfeil, Eugen Feist, Deutsche Vereinigung Morbus Bechterew e.V., Sklerodermie Selbsthilfe e.V., Deutsche Rheuma-Liga Bundesverband e. V., Martin Rudwaleit, Silke Zinke, Felix Mühlensiepen.

Funding Open Access funding enabled and organized by Projekt DEAL.

\section{Declarations}

Conflict of interest Nothing to disclose for any of the authors.

Open Access This article is licensed under a Creative Commons Attribution 4.0 International License, which permits use, sharing, adaptation, distribution and reproduction in any medium or format, as long as you give appropriate credit to the original author(s) and the source, provide a link to the Creative Commons licence, and indicate if changes were made. The images or other third party material in this article are included in the article's Creative Commons licence, unless indicated otherwise in a credit line to the material. If material is not included in the article's Creative Commons licence and your intended use is not permitted by statutory regulation or exceeds the permitted use, you will need to obtain permission directly from the copyright holder. To view a copy of this licence, visit http://creativecommons.org/licenses/by/4.0/.

\section{References}

1. Cleaton N, Raizada S, Barkham N et al (2021) The impact of COVID-19 on rheumatology patients in a large UK centre using an innovative data collection technique: prevalence and effect of social shielding. Rheumatol Int. https://doi.org/10.1007/ s00296-021-04797-4

2. Bateman J, Mulherin D, Hirsch G et al (2020) Rapid distribution of information by SMS-embedded video link to patients during a pandemic. Lancet Rheumatol 2:e315-e316. https://doi.org/10. 1016/S2665-9913(20)30126-0

3. Kataria S, Ravindran V (2018) Digital health: a new dimension in rheumatology patient care. Rheumatol Int 38:1949-1957. https:// doi.org/10.1007/s00296-018-4037-x

4. Self-Monitoring of Blood GlucoselDiabetes Technology \& Therapeutics. https://www.liebertpub.com/doi/full/10.1089/dia.2019. 2501. Accessed 17 Feb 2021

5. Heneghan CJ, Garcia-Alamino JM, Spencer EA et al (2016) Self-monitoring and self-management of oral anticoagulation. Cochrane Database Syst Rev. https://doi.org/10.1002/14651858. CD003839.pub3

6. Qu Y, Brady K, Apilado R et al (2017) Capillary blood collected on volumetric absorptive microsampling (VAMS) device for monitoring hydroxychloroquine in rheumatoid arthritis patients. J Pharm Biomed Anal 140:334-341. https://doi.org/10.1016/j. jpba.2017.03.047

7. Proft F, Spiller L, Redeker I et al (2020) Comparison of an online self-referral tool with a physician-based referral strategy for early recognition of patients with a high probability of axial spa. Semin Arthr Rheum 50:1015-1021. https://doi.org/10.1016/j.semarthrit. 2020.07.018

8. Kernder A, Morf H, Klemm P et al (2021) Digital rheumatology in the era of COVID-19: results of a national patient and physician survey. RMD Open 7:e01548. https://doi.org/10.1136/rmdop en-2020-001548

Publisher's Note Springer Nature remains neutral with regard to jurisdictional claims in published maps and institutional affiliations. 